\title{
Consistency of Blood Pressure Control: a Useful Tool of Hypertension Assessment in a Vulnerable Population
}

\author{
Anthi Katsouli, MD, MPH', Tanu S. Pandey, MD, $\mathrm{MPH}^{2}$, and David Goldberg, $\mathrm{MD}^{2}$
}

'Department of Internal Medicine, Loyola University of Medical Center, Maywood, IL, USA; ²Department of Medicine, John H. Stroger, Jr. Hospital of Cook County, Chicago, IL, USA.

J Gen Intern Med 34(12):2711-3

DOI: $10.1007 /$ s11606-019-05299-7

(C) Society of General Internal Medicine 2019

\section{INTRODUCTION}

There is strong evidence that treatment of hypertension reduces cardiovascular morbidity and mortality. ${ }^{1}$ National Health and Nutrition Examination Survey (NHANES) and a national quality program, the Health Plan Employer Data and Information Set (HEDIS), use point prevalence of blood pressure with a cut point of less than $140 / 90 \mathrm{mmHg}$ to assess control for the population and for clinical practices, respectively. ${ }^{2,3}$

There is compelling data showing that the proportion of visits with blood pressure control below 140/90 is a graded predictor of hypertension-related outcomes. ${ }^{4}$ The implication of this study is that beyond point prevalence of hypertension control, consistency of control below 140/90 may be an important patient-centered goal of care.

\section{METHODS}

We conducted an electronic medical record (EMR) review of patients in a primary care clinic at John H. Stroger, Jr. Hospital of Cook County approved by our institutional review board. Patients seen over a 2-week period of a random month of the year were selected using a random sampling method. An established primary care patient was defined as one with five or more clinic visits in the three preceding years. A diagnosis of hypertension was determined from the problem list. The last five clinic blood pressures recorded by the clinic nursing staff were abstracted for established clinic patients with hypertension.

Blood pressure control was defined as $<140 / 90 \mathrm{mmHg}$. For each participant, we evaluated the number of visits with blood pressure control and control at the last visit. Consistent control was defined as control on 4 or 5 of the visits. We defined inconsistent control as those with 3 or fewer of the five visits with controlled blood pressure.

The distribution of clinical predictors was compared between subjects with consistent and inconsistent control with chi-square tests. Independent predictors were identified using multivariate logistic regression. We developed multivariate

Published online September 12, 2019 models defining the race/ethnicity as a dichotomous variable (African-American vs. other race/ethnicity) because the sample size of each non-African-American race/ethnicity was small. We used the number of visits during the 3-year timeframe as a dichotomous variable with a cut-point of 9 visits, as this bivariate association with consistency of

Table 1 Baseline Characteristics of Patients with Inconsistent and Consistent BP Control

\begin{tabular}{|c|c|c|c|}
\hline & $\begin{array}{l}\text { Inconsistent } \\
\text { control }(n=87)\end{array}$ & $\begin{array}{l}\text { Consistent } \\
\text { control }(n=63)\end{array}$ & $\begin{array}{l}p \\
\text { value }\end{array}$ \\
\hline \multicolumn{4}{|l|}{ Demographics } \\
\hline \multicolumn{4}{|l|}{ Age } \\
\hline$\leq 54$ & $31(35.63 \%)$ & $15(23.81 \%)$ & 0.3 \\
\hline $55-64$ & $16(18.39 \%)$ & $17(26.98 \%)$ & \\
\hline $65-74$ & $22(25.29 \%)$ & $20(31.75 \%)$ & \\
\hline$\geq 75$ & $18(20.69 \%)$ & $11(17.46 \%)$ & \\
\hline \multicolumn{4}{|l|}{ Gender } \\
\hline Female & $49(56.32 \%)$ & $38(60.32 \%)$ & 0.62 \\
\hline Male & $38(43.68 \%)$ & $25(39.68 \%)$ & \\
\hline \multicolumn{4}{|l|}{ Race/ethnicity } \\
\hline African- & $67(77.01 \%)$ & $36(57.14 \%)$ & 0.01 \\
\hline \multicolumn{4}{|l|}{ American } \\
\hline Others & $20(22.99 \%)$ & $27(42.86 \%)$ & \\
\hline \multicolumn{4}{|l|}{ Current smoking } \\
\hline Yes & $8(9.2 \%)$ & $8(12.7 \%)$ & 0.49 \\
\hline No & $79(90.8 \%)$ & $55(87.3 \%)$ & \\
\hline \multicolumn{4}{|c|}{ BMI (CDC categories) } \\
\hline Normal & $18(20.69 \%)$ & $9(14.29 \%)$ & 0.6 \\
\hline Overweight & $26(29.89 \%)$ & $21(33.33 \%)$ & \\
\hline Obese & $43(49.43 \%)$ & $33(52.38 \%)$ & \\
\hline \multicolumn{4}{|l|}{ Comorbidities } \\
\hline Diabetes mellitus & $52(59.77 \%)$ & $34(53.97 \%)$ & 0.48 \\
\hline Chronic kidney & $27(31.03 \%)$ & $12(19.05 \%)$ & 0.1 \\
\hline $\begin{array}{l}\text { disease } \\
\text { Coronary artery }\end{array}$ & & & \\
\hline $\begin{array}{l}\text { Coronary artery } \\
\text { disease }\end{array}$ & $11(12.64 \%)$ & $12(19.05 \%)$ & 0.28 \\
\hline \multicolumn{4}{|l|}{ disease } \\
\hline $\begin{array}{l}\text { Stroke } \\
\text { Congestive heart }\end{array}$ & $6(6.9 \%)$ & $6(9.52 \%)$ & 0.56 \\
\hline $\begin{array}{l}\text { Congestive heart } \\
\text { failure }\end{array}$ & $14(16.09 \%)$ & $15(23.81 \%)$ & 0.24 \\
\hline Dyslipidemia & $67(77.01 \%)$ & $51(80.95 \%)$ & 0.56 \\
\hline \multicolumn{4}{|l|}{ Number of visits } \\
\hline $5-6$ & $30(35.29 \%)$ & $13(21.31 \%)$ & 0.23 \\
\hline $7-8$ & $16(18.82 \%)$ & $10(16.39 \%)$ & \\
\hline $9-10$ & $18(21.18 \%)$ & $13(21.31 \%)$ & \\
\hline $11-12$ & $9(10.59 \%)$ & $12(19.67 \%)$ & \\
\hline$\geq 13$ & $12(14.12 \%)$ & $13(21.31 \%)$ & \\
\hline \multicolumn{4}{|l|}{ Number of visits } \\
\hline$<9$ & $48(55.17 \%)$ & $25(39.68 \%)$ & 0.06 \\
\hline$\geq 9$ & $39(44.83 \%)$ & $38(60.32 \%)$ & \\
\hline \multicolumn{4}{|c|}{ Number of hypertensive medications } \\
\hline $0-1$ & $12(13.79 \%)$ & $15(23.81 \%)$ & 0.19 \\
\hline 2 & $25(28.74 \%)$ & $14(22.22 \%)$ & \\
\hline 3 & $26(29.89 \%)$ & $23(36.51 \%)$ & \\
\hline$\geq 4$ & $24(27.59 \%)$ & $11(17.46 \%)$ & \\
\hline
\end{tabular}


hypertension control approached statistical significance at this level. We used backward elimination with a threshold of $p<$ 0.05 for eliminating variables in the model. The outcomes were adjusted for age and gender in the model. We report the risk as an odds ratio with $95 \%$ confidence intervals. The statistical analysis was conducted using SAS 9.2 (English).

\section{RESULTS}

We reviewed 258 charts; 150 (58\%) met the inclusion criteria. Among the 108 excluded patients, 62 had hypertension but fewer than five clinic visits. The mean age was 63 years (range 23-90), 58\% were women, and 69\% were African-American
(13\% Hispanic, 11\% White, and 5\% Asian). The most common comorbidities were dyslipidemia (79\%) and diabetes (57\%). Table 1 describes additional variables of the study population.

Eighty-three subjects (55\%) had controlled blood pressure at the last visit. Figure 1 shows the subject's consistency of blood pressure control. Sixty-four individuals (43\%) met the study definition of consistent control. Fifty individuals (33\%) had control at 2 or 3 visits (sometimes controlled) and 36 individuals (24\%) had control at 0 or 1 visits (never/rarely controlled). Among those with controlled hypertension at the last visit, $68 \%(n=53)$ had consistent control. Among those with uncontrolled hypertension at the last visit, $10 \%(n=7)$ had consistent control.

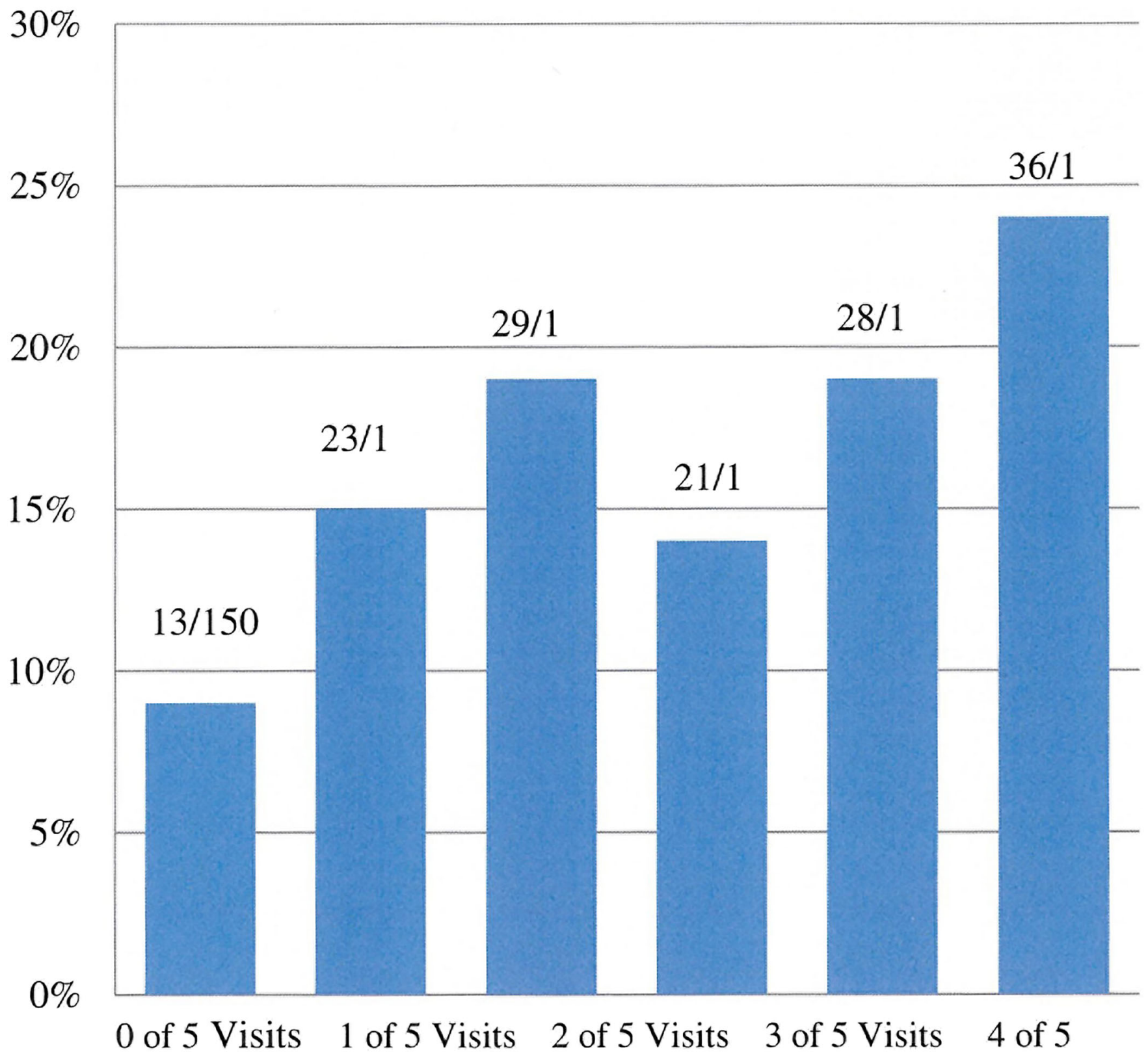

Figure 1 Proportion of patients with blood pressure controlled to $<140 / 90$ at the five recorded visits. 


\section{DISCUSSION}

In this retrospective chart review in a public hospital primary care clinic, the point prevalence of control on treatment (55\%) is below the NHANES US population rate. We found that $43 \%$ met our definition for consistent control.

Using the frame of consistency of hypertension control may provide clinically meaningful information beyond the point prevalence of hypertension control. Given the known variability of blood pressure, ${ }^{5}$ it stands to reason that point prevalence would not fully predict consistent control. In our population, one-third of patients with point prevalence of control did not have consistent control. These are patients in whom we would recommend on-going careful monitoring. The frame of consistency may influence clinical decision-making, helping overcome clinical inertia. ${ }^{6}$ The hypotheses that integration of consistency of blood pressure control alters clinical judgment, provider-patient communication, and is of value to aggregate assessment and clinical quality improvement are each testable.

Corresponding Author: Anthi Katsouli, MD, MPH; Department of General Internal Medicine Loyola University of Medical Center, Maywood, IL, USA (e-mail: Anthi.Katsouli@lumc.edu).

\section{Compliance with Ethical Standards:}

We conducted an electronic medical record (EMR) review of patients in a primary care clinic at John H. Stroger, Jr. Hospital of Cook County approved by our institutional review board.
Conflict of Interest: The authors declare that they do not have a conflict of interest.

\section{REFERENCES}

1. James PA, Oparil S, Carter BL, Cushman WC, Dennison-Himmelfarb C, Handler J, Lackland DT, LeFevre ML, MacKenzie TD, Ogedegbe $O$, Smith SC, Svetkey LP, Taler SJ, Townsend RR, Wright JT. Narva AS, Ortiz E. 2014 evidence-based guideline for the management of high blood pressure in adults: Report from the panel members appointed to the Eighth Joint National Committee (JNC 8). JAMA. 2014;311:507-520.

2. Egan BM, Zhao Y, Axon RN. US trends in prevalence, awareness, treatment, and control of hypertension, 1988-2008. JAMA. 2010;303:2043-50.

3. Patel MM, Datu B, Roman D, Barton MB, Ritchey MD, Wall HK, Loustalot F. Progress of health plans towards meeting the million hearts clinical target for high blood pressure control - United States, 2010-2012. MMWR. 2014;63:127-130.

4. Mancia G, Messerli F, Bakris G, Zhou Q, Champion A, Pepine CJ. Blood pressure control and improved cardiovascular outcomes in the international Verapamil SR-Trandolapril study. Hypertension. 2007;50:299-305.

5. Rothwell PM, Howard SC, Dolan E, O'Brien E, Dobson JE, Dahlöf B, Sever PS, Poulter NR. Prognostic significance of visit-to-visit variability, maximum systolic blood pressure, and episodic hypertension. Lancet. 2010;375:895-905.

6. Huebschmann AG, Mizrahi T, Soenksen A, Beaty BL, Denberg TD. Reducing clinical inertia in hypertension treatment: a pragmatic randomized controlled trial. J Clin Hypertens. 2012;14:322-9.

Publisher's Note Springer Nature remains neutral with regard to jurisdictional claims in published maps and institutional affiliations. 